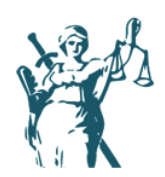

JUSTICIA

ISSN impreso 0124-7441

\title{
Análisis a la protección del Estado a los ecosistemas de páramo
}

\section{Analysis to the protection of the state to the ecosystems of moor ${ }^{1}$}

\author{
Ana Emilse Garcia Bustamante \\ Universidad Libre Seccional Cúcuta, Colombia) \\ ana.garcia@unilibrecucuta.edu.co \\ Yamal Elias Leal Espear \\ Universidad Libre Seccional Cúcuta, Colombia \\ yamal.leal@unilibrecucuta.edu.co
}

Recibido: 5 de marzo de 2018 / Aceptado: 19 de mayo de 2018 https://doi.org/10.17081/just.24.3400

\section{Resumen}

El presente artículo de revisióntiene por objeto analizar un tema fundamental para la supervivencia de la especie humana como lo es la preservación de los Ecosistemas de Páramo o también llamadas fábricas de agua. Los páramos gozan de especial protección en el ámbito internacional a través de la suscripción de diferentes convenios, entre los que se destaca: "el Convenio de Diversidad Biológica", como en el ámbito nacional mediante un conjunto de Leyes, Decretos, Resoluciones y Sentencias de la Corte Constitucional Colombiana que buscan que no desaparezcan los ecosistemas de páramos que gozan de una singular riqueza cultural, biótica y con un alto grado de especies de flora y fauna endémicas de inmenso valor, que constituyen un factor indispensable para el equilibrio ecosistémico, el manejo de la biodiversidad y del patrimonio natural del país. Por lo tanto, se realizó un análisis a la protección brindada por el Estado Colombiano a los ecosistemas de páramos, partiendo de la revisión de los convenios internacionales suscritos por los diferentes Estados, así como la normatividad ambiental existente, en concordancia con los precedentes jurisprudenciales, donde se puede concluir de acuerdo a los documentos analizados, que a pesar de existir un desarrollo legislativo y reglamentario amplio, es poco lo que se hace para evitar acabar con las fábricas de agua (páramos) ante el avance desmedido de la explotación de recursos naturales no renovables (carbón, oro) y al desarrollo económico.

Palabras clave: Ecosistemas, Páramo, Biodiversidad, Fundamental, Conservación, Bioma, Recurso Hídrico.

\section{Abstract}

The present review article aims to analyze a fundamental issue for the survival of the human species such as the preservation of the Ecosystems of Paramo or also called water factories. Paramos enjoy special protection at the international level through the signing of different conventions, including: "the

I El presente artículo es inédito y se clasifica como un artículo de investigación cuyo título es: "La importancia de los procesas de delimitación de zonas de paramo en el Departamenta Norte de Santander (recursas naturales)", del grupo de investigación en Derecho Público GIDPÚ y del Semillero de Derecho Ambiental y Crecimienta Sastenimienta de nambre "Ramsar" de la Universidad Libre, Seccional Cúcuta.

Justicia Vol. No. 35: pp. 166-180. Enero-Junio, 2019. DOI: 10.17081/just.24.35.3400

(c) Copyright 2019 by González Bolívar, D.

$$
\text { open } 2 \text { access @) (i) }
$$


intergovernmental agreement" Ramsar "and the Convention on Biological Diversity", as well as at the national level through a set of laws, Decrees, Resolutions and Judgments of the Colombian Constitutional Court that seek to ensure that the ecosystems of páramos that enjoy a unique cultural richness, biotic and with a high degree of endemic species of flora and fauna of immense value, that are an indispensable factor For the ecosystem balance, the management of the biodiversity and the natural heritage of the country. Therefore, an analysis was made of the protection provided by the Colombian State to the páramos ecosystems, starting from the revision of the international agreements signed by the different States, as well as the existing environmental regulations, in agreement with the precedents jurisprudenciales, Where it can be concluded according to the analyzed documents, that although there is a broad legislative and regulatory development, little is done to avoid ending the water mills (páramos) in the face of the excessive progress of the exploitation of natural resources Non-renewa.

Key words. Ecosystems, Paramo, Biodiversity, Fundamental, Conservation, Biome, Water Resource.

\section{Como citar:}

Albarán Gómez, A. (2019). Poder naval para el desarrollo marítimo de la nación: del realismo a la cooperación internacional. Justicia, 24(35). https://doi.org/10.17081/just.24.35.338 


\section{INTRODUCCIÓN.}

Con la entrada en vigencia de la Constitución de 1991, se establece como unos de los fines esenciales del Estado en el artículo segundo, la protección del medio ambiente, estableciéndolo como un deber, el cual es desarrollado a través de una serie de disposiciones como por ejemplo: Ley 99 de 1993, Ley 373 de 1997, Ley 162 de 1994, Decreto-ley 2811 de 1974, Resolución 769 de 2002, que denotan la importancia que tiene en nuestro ordenamiento jurídico el medio ambiente al punto de determinar que es una obligación Estatal la protección a la diversidad e integridad del ambiente.

Sin embargo, ese deber de protección del medio ambiente es vulnerado, cuando por ejemplo se pretende la explotación de un recurso no renovable en especial en zonas donde se presenta un ecosistema de páramo.

Esas explotaciones de recursos no renovables por lo general van acompañadas de obras de infraestructura que generan además la abstracción de cantidades importantes de agua que impactan negativamente en la flora y fauna colocando en riesgo la vida como la conocemos por lo que en este contexto es necesario conciliar el grave impacto ambiental que genera la explotación de recursos no renovables (por ejemplo carbón, oro) con la protección de la biodiversidad y el derecho a un medio ambiente sano.

\section{METODOLOGÍA.}

Se utilizó el enfoque cualitativo, con el propósito de analizar la protección de los ecosistemas de páramo, y las medias adoptadas por el Estado para materializar dicha protección en el marco jurídico colombiano, realizando un análisis documental hermenéutico de los precedentes jurisprudenciales, haciendo énfasis en la importancia de los ecosistemas del páramo como fuente del recurso hídrico para sobrevivencia de la especie humana.

\section{RESULTADOS.}

\subsection{Protección a los ecosistemas de páramo, un problema mundial.}

La conservación de la diversidad biológica es un interés común de todos los Estados, pues son "conscientes del valor intrínseco de la diversidad biológica y de los valores ecológicos, genéticos, sociales, económicos, científicos, educativos, culturales, recreativos y estéticos" (Naciones Unidas, 1992, p 1) es por ello que se han establecido áreas protegidas para conservar dicha diversidad biológica dada su importancia ecológica como los ecosistemas de páramo.

En el plano internacional existe un marco regulatorio amplio para la protección de los páramos, como la Conferencia de Naciones Unidas sobre el Medio Humano, celebrada en Estocolmo en 1.972 en la que se adoptó el siguiente principio:

"El hombre tiene el derecho fundamental ([al disfrute] de condiciones de vida adecuadas en un medio de calidad tal que le permita llevar una vida digna y gozar de bienestar, y tiene la solemne obligación de proteger y mejorar el medio para las generaciones presentes y futuras" (Temas Educativos, 1972, p. 32). 
Así mismo,

en 1992 se celebró la Conferencia de las Naciones Unidas sobre el Medio Ambiente y Desarrollo, "Cumbre de la Tierra", en Rio de Janeiro (Brasil), en donde se acordaron una serie de estrategias para establecer el desarrollo sustentable. Uno de los principales acuerdos firmados en la Cumbre de la Tierra fue el Convenio de Diversidad Biológica (CBD), inspirado por el creciente compromiso de la comunidad global con la conservación y el aprovechamiento sustentable de la biodiversidad. (Biodiversidad mèxicana, 2016, p. 6).

“Colombia es Parte del Convenio de Diversidad Biológica (CDB), mediante la Ley 165 de 1994 y entró en vigor para el país el 26 de febrero de 1995. El CBD tiene los siguientes tres objetivos: 1) conservación de la biodiversidad, 2) Uso sostenible de la biodiversidad, y 3) Participación justa y equitativa de los beneficios derivados del uso de la biodiversidad" (Cancilleria, s.f.b, p. 1).

Es importante resaltar que la Corte Constitucional Colombiana declaro la exequibilidad del "Convenio sobre la Diversidad Biológica" hecho en Río de Janeiro el día 5 de junio de 1992, y de la Ley 162 de 1994, manifestando lo siguiente:

Esta Corporación es consciente de que si bien la protección jurídica del derecho a gozar un ambiente sano es uno de los pilares esenciales del desarrollo social, la Constitución se ocupó también de regular otros temas de orden ecológico como es el caso de la biodiversidad, de la conservación de áreas naturales de especial importancia, del desarrollo sostenible, de la calidad de vida y de la educación y la ética ambiental, los cuales constituyen, de igual forma, el estandarte mínimo para la necesaria convivencia de los asociados dentro de un marco de bienestar general. Colombia es uno de los países que mayor interés debe tener respecto de los acuerdos internacionales en materia de biodiversidad. La razón es, por lo demás, sencilla: nuestro país ha sido reconocido a nivel mundial como uno de los centros biológicos de mayor diversidad. (C.Const. 1994).

\subsection{Protección a los ecosistemas de páramo en colombia.}

De conformidad con las normas Constitucionales y el Convenio de Diversidad Biológica (CDB), se ha contado con un desarrollo legislativo amplio en el ordenamiento jurídico Colombiano, prueba de ello tenemos que la Ley 99 de 1993 en su artículo 1 numeral 4 describe como uno de los principios generales en materia ambiental lo siguiente: "Las zonas de páramos, subpáramos, los nacimientos de agua y las zonas de recarga de acuíferos serán objeto de protección especial" (Congreso de Colombia, 1993).

La Corte Constitucional Colombiana ha venido resaltando la importancia sobre la protección a la biodiversidad y a gozar de un ambiente sano, debido a su inescindible relación con la vida, haciendo énfasis en los diferentes instrumentos con los que cuenta el Estado y el ciudadano para hacer efectivo su derecho a un entorno ecológico sano al señalar:

La importancia del tema ecológico, y en particular la defensa del derecho a gozar de un ambiente sano, ha sido objeto de especial interés por parte de las autoridades judiciales colombianas, y en particular de la Corte Constitucional. En efecto, mediante la jurisprudencia de esta Corporación, al revisar las acciones de tutela, se ha establecido que el derecho a un ambiente sano, debido a su inescindible relación con la vida, la integridad física y la salud de los asociados, 
es un derecho fundamental que puede ser protegido a través del mecanismo consagrado en el artículo 86 de la Carta. Al respecto, se ha señalado:

El derecho al medio ambiente no se puede desligar del derecho a la vida y a la salud de las personas. De hecho, los factores perturbadores del medio ambiente causan daños irreparables en los seres humanos y si ello es así habrá que decirse que el medio ambiente es un derecho fundamental para la existencia de la humanidad. A esta conclusión se ha llegado cuando esta Corte ha evaluado la incidencia del medio ambiente en la vida de los hombres y por ello en Sentencias anteriores de tutelas, se ha afirmado que el derecho al medio ambiente es un derecho fundamental. (C. Const, 1994).

En el mismo sentido la Corte Constitucional ha dicho:

Aparece entonces dentro de las diferentes acepciones que se le han dado a la Carta Política de 1991, la de Constitución ecológica. [T-411-1992]. Se trata de una normatividad que no se limita única y exclusivamente a consagrar principios generales, sino que le otorga al Estado y a los ciudadanos instrumentos efectivos para convivir, en la medida de lo posible, dentro de un entorno ecológico sano. (C. Const, 1994).

También encontramos en el ordenamiento jurídico Colombiano que el Ministerio de Ambiente, mediante Resolución 769 de 2002, emitio una serie de disposiciones tendientes a la protecciòn de los parámos, resaltando que en los considerandos de la Resoluciòn manifesto:

Que los páramos son ecosistemas de una singular riqueza cultural y biótica y con un alto grado de especies de flora y fauna endémicas de inmenso valor, que constituyen un factor indispensable para el equilibrio ecosistémico, el manejo de la biodiversidad y del patrimonio natural del país.

Que a pesar de existir avances en el conocimiento de la oferta natural del ecosistema de páramo, se requiere profundizar en el entendimiento de las interrelaciones entre éstos y las actividades humanas, así como en el estudio de su vulnerabilidad frente al cambio climático global, con el fin de gestionar planes, programas, proyectos y/o actividades que permitan adoptar medidas de manejo y adaptación a los cambios naturales.

Que los páramos vienen siendo usados y degradados por actividades antrópicas como el establecimiento de monocultivos, las quemas y la ganadería extensiva, ocasionando compactación y empobrecimiento de suelos, pérdida de materia orgánica, cobertura vegetal y diversidad biológica, erosión y contaminación de suelos y aguas. (Ministerio del medio ambiente, 2002).

Así mismo en la Resolución 769 de 2002 en el artículo 2 presenta una definiciòn de páramo en los siguientes tèrminos:

Ecosistema de alta montaña, ubicado entre el límite superior del bosque andino y, si se da el caso, con el límite inferior de los glaciares o nieves perpetuas, en el cual domina una vegetación herbácea y de pajonales, frecuentemente frailejones y pueden haber formaciones de bosques bajos y arbustivos y presentar humedales como los ríos, quebradas, arroyos, turberas, pantanos, lagos y lagunas. Comprende tres franjas en orden ascendente: El subpáramo, el páramo propiamente dicho y el superpáramo. Los límites altitudinales en que se ubican estos ecosistemas varían entre las cordilleras, debido a factores orográficos y climáticos locales. La intervención 
antrópica también ha sido un factor de alteración en la distribución altitudinal del páramo, por lo cual se incluyen en esta definición los páramos alterados por el hombre (Ministerio del medio ambiente, 2002).

Otra de las medidas de protección a los Paramos es la establecida en el artículo 16 de la Ley 373 de 1997 (Congreso de Colombia, 1997) donde se adopta el programa para el uso eficiente y ahorro del agua:

Protección de zonas de manejo especial. En la elaboración y presentación del programa se debe precisar que las zonas de páramo, bosques de niebla y áreas de influencia de nacimientos de acuíferos y de estrellas fluviales, deberán ser adquiridos con carácter prioritario por las entidades ambientales de la jurisdicción correspondientes, las cuales realizarán los estudios necesarios para establecer su verdadera capacidad de oferta de bienes y servicios ambientales, para iniciar un proceso de recuperación, protección y conservación. (Congreso de Colombia, 1997).

En el mismo sentido, el Ministerio del Medio Ambiente, a través de la Resolución 769 de 2002 en artículo 8 dispuso lo siguiente:

Áreas de interés público. Las autoridades ambientales incluirán en sus planes de acción trianual, además de las estrategias, programas, proyectos y acciones enfocadas a la protección, conservación, manejo sostenible y restauración de los páramos del área de su jurisdicción, las actividades a desarrollar con los departamentos y municipios para dar cumplimiento a lo establecido en el artículo 111 de la Ley 99 de 1993, sobre adquisición de áreas de interés para acueductos municipales y distritales y en el artículo 16 de la Ley 373 de 1997, sobre la adquisición con carácter prioritario de las zonas de páramos, bosques de niebla y áreas de influencia de nacimientos de acuíferos y de estrellas fluviales, por las entidades ambientales de la jurisdicción correspondiente. (Ministerio del medio ambiente, 2002).

En Colombia con la expedición de la Resolución 769 de 2002, se planteó la necesidad de conciliar entre las actividades humanas y los páramos, es por ello que en el capítulo segundo se establecieron unas medidas de protección, conservación, manejo sostenible y restauración de los páramos donde el Instituto de Investigación Alexander Von Humbolt, participa en el estudio técnico del estado actual de los páramos.

En relación con la actividad minera, para efectos de la determinación de las Zonas Exclusivas de la Minería, el artículo 3 de la Ley 1382 de 2010, introdujo la prohibición de desarrollar actividades de exploración y explotación de minerales en zonas delimitadas por la autoridad ambiental como páramo. Para lo anterior se dispuso que los ecosistemas de páramo se identificaran con la información cartográfica proporcionada Instituto de Investigación Alexander Von Humbolt. (Congreso de Colombia, 2010).

La ley del Plan de Desarrollo 2010-2014 "Prosperidad para todos" (Ley 1450 de 2011) en su artículo 202 ratificó la exclusión de la minería y la amplió a la agricultura y los "humedales Ramsar". La misma ley pide la delimitación de los páramos a escala 1:25.000 con base en "estudios técnicos, económicos, sociales y ambientales", la cual debe ser adoptada mediante acto administrativo por el Ministerio del Ambiente y las Corporaciones Autónomas Regionales, y los otros entes ambientales, quienes deben luego zonificar su régimen de usos (Pérez, 2013, pp 127-128) 
Posteriormente, en la Ley 1753 de 2015, por la cual se expidió el Plan Nacional de Desarrollo 2014-2018 "Todos por un nuevo país", se estableció en el artículo 173 lo siguiente:

Protección y delimitación de páramos. En las áreas delimitadas como páramos no se podrán adelantar actividades agropecuarias ni de exploración o explotación de recursos naturales no renovables, ni construcción de refinerías de hidrocarburos.

El Ministerio de Ambiente y Desarrollo Sostenible hará la delimitación de las áreas de páramos al interior del área de referencia definida en la cartografía generada por el Instituto Alexander Von Humboldt a escala 1:100.000 o 1:25.000, cuando esta última esté disponible. En esta área, la autoridad ambiental regional deberá elaborar los estudios técnicos que permitan caracterizar el contexto ambiental, social y económico, de conformidad con los términos de referencia expedidos por el Ministerio de Ambiente y Desarrollo Sostenible. Al interior de dicha área, el Ministerio de Ambiente y Desarrollo Sostenible deberá delimitar el área de páramo, con base en criterios técnicos, ambientales, sociales y económicos. (Congreso de Colombia, 2015, p. 31).

La Corte Constitucional Colombiana, se ha referido al deber del Estado de delimitar las zonas de páramo, así por ejemplo en la Sentencia C-035 de 2016 manifestó:

Como se puede observar, la norma establece el deber legal de delimitar los páramos en cabeza del Ministerio de Ambiente y Desarrollo Sostenible, y crea un procedimiento para su delimitación. Conforme a este procedimiento, en un primer momento el IAvH elabora un área de referencia que debe presentar ante el Ministerio de Ambiente y Desarrollo Sostenible, para que dicha cartera ministerial realice la delimitación del páramo mediante acto administrativo. Ahora bien, cabe resaltar que si bien el área de referencia propuesta por el IAvH debe servir de fundamento científico- ambiental al Ministerio de Ambiente y Desarrollo Sostenible para adoptar la delimitación, dicha entidad no está obligada a basarse en el área de referencia presentada por el $\mathrm{IAvH}$ como área delimitada. Más aun, la ley no define una serie de parámetros, criterios u orientaciones, que deba seguir el Ministerio de Ambiente al delimitar los páramos. En esa medida, si el Ministerio no está obligado a seguir los criterios utilizados por el IAvH, ni existen criterios a los cuales deba sujetarse en el ejercicio de su obligación de delimitar los páramos de nuestro país, es necesario concluir que la cartera de ambiente podría tener un margen de total discrecionalidad para la determinación del área definitiva de páramo. (C. Const. 2016).

\subsection{La importancia del páramo como fuente del recurso hídrico en colombia.}

La importancia de proteger los ecosistemas de páramo como abastecimiento de agua en Colombia se puede resumir según Cleef, (2013) así: "Colombia es considerada como el país núcleo de los páramos debido a que posee la mitad de la superficie de estos ecosistemas a nivel mundial, que albergan una enorme y singular diversidad biológica, además de la heterogeneidad, que se encuentra distribuida en las tres cordilleras" (p. 4).

Normalmente en Colombia se presentan valores de precipitación alrededor de $1000 \mathrm{~mm} / \mathrm{año}$

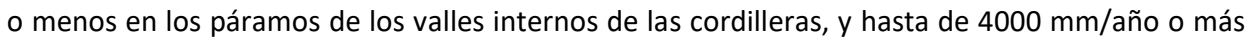
en las vertientes expuestas a los vientos alisios o a las lluvias y vientos del Pacífico. Sin embargo, algunos páramos ubicados en la sombra de las lluvias son más secos, como por ejemplo, el Páramo de Berlín (Santander), actualmente transformado, y otros páramos ubicados en las cabeceras del Valle del Chicamocha (Cleef, 2013, p.7). 
"Los páramos son los mayores proveedores de agua para las regiones andinas de Ecuador, Colombia, Venezuela y Perú. Además, muchos de los grandes ríos se originan en estos ecosistemas" (Vasquez \& Buitrago, 2011, p. 30).

"Regulación del agua: la capacidad de los suelos y vegetación de los páramos para almacenar y luego liberar reguladamente el agua, hace de estos ecosistemas el lugar de origen de lagunas, quebradas y ríos. De allí que aproximadamente el $70 \%$ del agua que llega a las grandes ciudades de los Andes provenga de los páramos" (Vasquez \& Buitrago, 2011, p. 8).

"Para el caso colombiano podríamos afirmar que la mayor acumulación de agua es hidrogeológica, es decir, es agua almacenada en depósitos subterráneos conocidos como acuíferos" (Vasquez \& Buitrago, 2011, p. 32).

"Nuestros páramos surten de agua dulce a ríos, quebradas y lagunas de zonas más bajas y acuíferos. Esto quiere decir que muchos de los distritos de riego y acueductos de zonas urbanas y rurales reciben de allí el agua para consumo humano, producción de alimentos, diferentes industrias, entre otros usos" (Vasquez \& Buitrago, 2011, p. 33).

Para Cortés y Sarmiento (2013) “el páramo es un sitio clave donde se presenta la 'cosecha' de agua de las lluvias y nieblas que se almacena en lagunas glaciares, turberas, pantanos y en los suelos humíferos" (p. 4) y que es retenida por un periodo relativamente largo y liberada lenta y constantemente.

La Corte Constitucional (2016) resalta que: “debido a la función retenedora y proveedora de agua dulce es que se afirma que estos ecosistemas son reguladores del ciclo hídrico o "productores de agua" (p. 131). Dicha función resulta de suma importancia, pues ello impacta de forma positiva en la calidad, disponibilidad y accesibilidad del recurso.

Por otra parte, el páramo presta un servicio ambiental como sistema de captura de carbono, pues según Mayorga (2016, p. 6) "el suelo más común en paramos es de origen volcánico y se conoce técnicamente como andosol, del japonés que significa 'tierra negra'. Este color negro viene del alto contenido de materia orgánica, que por las bajas temperaturas no se descompone rápidamente" (p. 6).

Por lo anterior, "los páramos forman complejos órganominerales, que contribuyen a aumentar la capacidad de retención y regulación del agua y el almacenamiento de carbono" (Cabrera \& Ramirez, 2014, p. 32). En esta medida, los páramos juegan un rol importante en la mitigación del cambio climático en tanto que se trata de depósitos naturales de carbono.

\subsection{Factores de vulnerabilidad y fragilidad del ecosistema de páramo}

Son varios los factores que afectan a los ecosistemas de páramo, entre otros el cambio climático, trayendo como consecuencias perjudiciales a los páramos las siguientes:

[...] en la alta montaña de la cordillera Central de Colombia se ha registrado un aumento de temperatura de $1.30 C$ por década (Ruiz et al. 2008) acompañado de reducción de humedad en los días soleados. En las series históricas de precipitación y temperatura de Colombia el IDEAM (2010), a través de índices de extremos climáticos, encontró: i) disminución de la precipitación media 
anual, ii) disminución de eventos extremos de lluvia en páramos y zonas aledañas, iii) incremento de eventos extremos de lluvia en los otros pisos térmicos (cálido, templado y frío), independientemente de la tendencia positiva o negativa en la precipitación total anual, iv) aumento de la temperatura máxima en el páramo alto $\left(1^{\circ} \mathrm{C}\right.$ por década), subpáramo y bosque altoandino $\left(0.3-0.6^{\circ} \mathrm{C}\right.$ por década), v) incremento en la temperatura mínima, menos pronunciado o incluso negativo en algunas estaciones de páramo negativo; vi) mayor incremento de temperatura media en el páramo alto (Andrade, 2013, p. 135).

Otro de los factores que afectan a los páramos es la remoción de la capa vegetal no sólo tiene un impacto en cuanto se refiere a la captura y almacenamiento de carbono. De un lado, el cambio de la naturaleza del suelo disminuye la capacidad del mismo para realizar el proceso de infiltración lenta del recurso hídrico que lo caracteriza. Por otra parte, la afectación sobre la flora y la fauna puede generar efectos adversos sobre el ecosistema, al alterarse ciertos procesos como la polinización, cambios en las redes tróficas, favoreciendo la aparición de especies invasoras que extinguen a las nativas (Vargas, 2013).

Teniendo en cuenta estos factores que afectan los páramos podemos concluir que son ecosistemas vulnerables, resaltando que su capacidad de recuperación es lenta en comparación con otros ecosistemas.

Es importante resaltar que el proceso de recuperación de un ecosistema de páramo es prácticamente imposible, según Fierro (2012), quien sobre este aspecto manifiesta que la restauración o recuperación de un ecosistema de páramo es prácticamente imposible, en la medida que es un ecosistema que evolucionó en un contexto geográfico estable, de manera relativamente aislada de factores de perturbación exógena, como los cambios de clima, los incendios, o la presencia humana. Al desarrollarse de manera aislada, la capacidad de adaptación de los diversos elementos que componen este bioma es bastante limitada. Por lo tanto, cuando las funciones ecosistémica de suelo y subsuelo sufren impactos negativos, suelen ser irreversibles.

Según Vargas, (2013), los ecosistemas de páramo tienen "umbrales de resistencia y resiliencia muy bajos" (pág. 41), es decir, son ecosistemas frágiles. Lo anterior se debe que, como se mencionó, son ecosistemas que evolucionaron en aislamiento geográfico, lo cual implica que no fueron sometidos a disturbios permanentes (bien fueran antrópicos o naturales) que permitieran que los páramos desarrollaran adaptaciones especiales.

Actualmente, los disturbios más comunes en los ecosistemas de páramo son: (i) el fuego; (ii) la ganadería; (iii) la agricultura; (iv) la minería a cielo abierto y de socavón; (v) las plantaciones de especies exóticas; (vi) la construcción de obras civiles; (vii) el corte de matorrales para leña; (viii) la presencia de especies invasoras, y (ix) la cacería. Como se puede observar, los ecosistemas de páramo han estado sometidos a una serie de disturbios que pueden acabar con estos ecosistemas en atención a su fragilidad. (C. Const. 2016).

Sobre estos temas la Corte Constitucional Colombiana se pronunció en los siguientes términos:

se destaca que, ante la vulnerabilidad, fragilidad y dificultad de recuperación de los ecosistemas de páramo, el Estado tiene a su cargo la obligación de brindar una protección más amplia y especial, dirigida específicamente a preservar este tipo de ecosistema. Lo anterior no sólo porque es un tipo de bioma que no es común en el mundo, sino también en razón de los importantes servicios ambientales que presta, sumado al hecho que en la actualidad es un 
ecosistema sometido a intervenciones negativas o disturbios que afectan su pervivencia. (C. Const. 2016).

Finalmente, encontramos que dentro de las principales causas de degradación de estos ecosistemas según la organización ambientalista Greenpace, han sido:

el establecimiento de cultivos de papa o amapola, y la introducción de ganado. Para poder sembrar en los páramos es necesario el desmonte y la quema de la vegetación natural, después de lo cual se adecua el suelo, fertilizándolo y arándolo para que pueda ser cultivado. La ganadería es un proceso muy similar, sólo que en lugar de sembrar cultivos se siembran pastos para que las vacas puedan alimentarse.

Al realizar todas las actividades anteriores la función de "esponja retenedora de agua" del páramo desaparece: ya no hay vegetación que capte agua, el suelo ha sido pisoteado por las vacas, maltratado por el hombre y ha perdido la porosidad que le permitía retener la humedad. En estas condiciones, el páramo ya no puede regular el ciclo del agua. En invierno, las fuertes lluvias arrasan con el suelo, erosionándolo y, además, los ríos se desbordan y se producen inundaciones que afectan a muchas personas. En verano se producen sequías severas, los caudales de los ríos se reducen o desaparecen $y$, por lo tanto, el agua que puede ser captada para abastecer a los habitantes de las regiones o ciudades cercanas también disminuye o se agota por completo. Lo anterior podría ser causa de graves desastres para ciudades en las que el agua proviene de los páramos casi en su totalidad. Sumado a los anteriores problemas, el acelerado calentamiento global afecta también a estos ecosistemas. Al aumentar la temperatura, las especies que están adaptadas a las condiciones típicas del páramo deben migrar a sitios más altos y fríos en busca de las condiciones ideales para su supervivencia. Con el tiempo, todo el ecosistema migra a las partes más altas de las montañas debido al cambio de clima. Los nevados son desplazados o desaparecen y el páramo pierde también parte de su extensión original (Greenpeace, 2009, pp. 6-7).

\section{DISCUSIÓN.}

Los páramos son ecosistemas típicos de las altas montañas donde nacen un gran número de quebradas y ríos muy importantes para el Estado Colombiano, dadas sus bajas temperaturas, resaltando que son bastante húmedos debido a sus fuertes precipitaciones; Sus suelos son pantanosos por su origen volcánico (andasol o tierra negra) donde viven plantas y animales. Además son los más hermosos e importantes ecosistemas y por esta razón los países que los poseen son privilegiados.

Para la Corte Constitucional Colombiana: “una delimitación inadecuada de los páramos, o que no consulte sólidos criterios científicos puede llegar a afectar los ecosistemas de páramo, con ello se podría causar un riesgo para la disponibilidad y la continuidad de servicios ambientales de los cuales depende el derecho fundamental al agua. Más aun, una delimitación inadecuada, podría llegar a permitir la utilización del suelo de los páramos para realizar actividades de minería y de hidrocarburos en estos ecosistemas.

De ser así, no sólo se permitiría el desarrollo de actividades mineras y de hidrocarburos a quienes cuenten con una licencia ambiental y/o un contrato de concesión anteriores a la prohibición, como lo establece el parágrafo primero del artículo 173 de la Ley 1753 de 2015 (Congreso Colombia, 2015), también se les permitiría desarrollar dichas actividades a cualquier persona que cuente con una licencia y contrato de concesión, independientemente de cuándo les 
haya sido expedida, pues formalmente tales áreas no serían parte de los páramos, por lo tanto no contarían con ningún tipo de protección especial.

\section{CONCLUSIONES.}

Colombia es altamente vulnerable a los impactos del cambio climático y, como señalan diversos estudios, con un aumento acelerado de la temperatura global del planeta sus efectos se sentirán a nivel social, económico y ambiental.

Con la degradación de los ecosistemas de páramo, se afecta gravemente el patrimonio natural de un país, al igual que ocurre con el histórico - artístico, ya este pertenece a las personas que en él viven, pero también a las generaciones venideras, puesto que estamos en la obligación y el desafío de entregar el legado que hemos recibido en condiciones óptimas a nuestros descendientes.

Sin embargo, en nuestro país aún desconocemos la importancia de los ecosistemas de páramo, sus características y los servicios que brinda a comunidades campesinas, indígenas y urbanas; a industrias y empresas, a hidroeléctricas, etc. Esta condición no ayuda a valorarlo y a cuidarlo.

El papel que cumplen los páramos en la regulación del ciclo hídrico y en la captura de carbono, hace que los Estados redoblen sus esfuerzos para lograr una protección supraestatal a estos ecosistemas estratégicos que son indispensables para garantizar no sólo la desaceleración del cambio climático, la biodiversidad y la riqueza de la nación, sino el derecho fundamental al agua del $70 \%$ de los colombianos.

\section{REFERENCIAS.}

Andrade, G. (2013). La delimitación del páramo y la incierta gestión de los servicios ecosistémicos de la alta montaña en escenarios de cambio ambiental. En J. Cortés, \& C. Sarmiento, Visión socioecosistémica de los páramos y la alta montaña colombiana: memorias del proceso de definición de criterios para la delimitación de páramos (págs. 127-139). Bogotá, D.C.: Min Ambiente y Instituto de Investigación de Recursos Biológicos Alexander von Humboldt.

Biodiversidad mèxicana. (2016). Convenio sobre la diversidad biològica. Obtenido de Biodiversidad mèxicana: http://www.biodiversidad.gob.mx/planeta/internacional/cbd.html

Cabrera, M., \& Ramírez, W. (2014). Restauración ecológica de los páramos de Colombia: transformación y herramientas para su conservación. IAvH. Bogotá.

Cancillería. (s.f.a). Convención Ramsar sobre Humedales de Importancia Internacional. Obtenido de http://www.cancilleria.gov.co/en/convencion-ramsar-sobre-humedales-importanciainternacional 
Cancilleria. (s.f.b). Convenio sobre Diversidad Biológica (CBD). Obtenido de http://www.cancilleria.gov.co/en/convenio-sobre-diversidad-biologica-cbd

Cleef, A. (2013). Origen, evolución, estructura y diversidad biológica de la alta montaña colombiana. Bogotá: Instituto de Investigación de Recursos Biológicos Alexander von Humboldt.

Congreso Colombia. (2015). Ley 1753 de 2015. Obtenido de http://www.mineducacion.gov.co/1759/articles-357047_recurso_1.pdf

Congreso de Colombia. (22 de diciembre de 1993). Ley 99 de 1993. Obtenido de http://www.alcaldiabogota.gov.co/sisjur/normas/Norma1.jsp?i=297

Congreso de Colombia. (6 de junio de 1997). Ley 373 de 1997. Bogotà, Colombia. Obtenido de http://www.minambiente.gov.co/images/normativa/leyes/1997/ley_0373_1997.pdf

Congreso de Colombia. (2010). Ley 1382 del 9 febrero de 2010. Obtenido de file://C:/Users/deimar/Downloads/ley138209022010.pdf

Corte Constitucional. (1994). Sentencia C-519/94. Bogotà, Colombia. Obtenido de http://www.corteconstitucional.gov.co/RELATORIA/1994/C-519-94.htm

Corte Constitucional República de Colombia. (8 de febrero de 2016). Sentencia C-035 de 2016 . Bogotá, Colombia. Obtenido de https://redjusticiaambientalcolombia.files.wordpress.com/2016/02/sentencia-c-035-2016paramos.pdf

Cortés, J., \& Sarmiento, C. (2013). Visión socioecosistémica de los páramos y la alta montaña colombiana: memorias del proceso de definición de criterios para la delimitación de páramos. Bogotà: Ministerio de Medio Ambiente y Desarrollo Sostenible y Instituto de Investigación de Recursos Biológicos Alexander von.

Cuesta Hinestroza, L., Nupan Mosquera, M. I., Ramírez Moreno, S., \& Palacios Lozano, L. G. (2016). El derecho a la participación en el trámite de licencias ambientales: ¿una garantía para la protección del medio ambiente? Revista Academia \& Derecho, 7 (12), 53-86.

Fierro, J. (2012). Políticas mineras en Colombia. Comité Catholique contre la faim et pour le développement - CCFD Terre Solidaire/Instituto Latinoamericano para una Sociedad y un Derecho Alternativos - ILSA. Bogotà: Digiprint Editores E.U.

Greenpeace. (diciembre de 2013). Páramos en Peligro: el caso de la minería de Carbón en Pisba. Obtenido

de http://www.greenpeace.org/colombia/Global/colombia/images/2013/paramos/12/Inform e\%20P\%C3\%A1ramos\%20en\%20peligro.pdf 
Greenpeace.org/colombia. (9 de noviembre de 2009). Cambio Climàtico: Futuro Negro para los Páramos. Obtenido de Greenpeace.org/colombia.: http://www.greenpeace.org/colombia/Global/colombia/informes/informe_todo3.pdf

Hofstede., R. (2013). Lo mucho que sabemos del páramo. Apuntes sobre el conocimiento actual de la integridad, la transformación y la conservación del páramo. En J. Cortés, \& C. Sarmiento, Visión socioecosistémica de los páramos y la (págs. 113-125). Bogotá: MinAmbiente.

Hoftede, R., Segarra, P., \& Mena, V. (2003). Los páramos del mundo. Proyecto Atlas Mundial de Páramos. Quito: Global Peatland Initiative/NC-UICN/EcoCiencia. Obtenido de http://www.portalces.org/sites/default/files/references/038_Hofstede\%20et\%20al.\%20(e ds).2003.Los\%20Paramos\%20del\%20Mundo.pdf

Mayorga, F. (31 de agosto de 2016). Los pàramos colombianos podrìn desaparecer como consecuencia del cambio climàtico. Blog. Obtenido de http://educacionoceanografica.blogspot.com.co/2016/08/los-paramoscolombianospodrian.html

Ministerio de Ambiente, Vivienda y Desarrollo Territorial. (1 de julio de 2010). Decreto nùmero 2372. 23. Bogotà, Colombia. Obtenido de http://www.minambiente.gov.co/images/normativa/decretos/2010/dec_2372_2010.pdf

178 Ministerio de Relaciones Exteriores. (1999). Decreto 2052, 1999. Decreto, Santafè de Bogotà. Obtenido de http://www.cdmb.gov.co/web/ciudadano/centro-de-descargas/380-decreto2052-de-1999-1/file

Ministerio del Medio Ambiente. (5 de agosto de 2002). Resoluciòn nùmero 769 de 2002. Bogotà, Colombia. Obtenido de http://www.bvsde.paho.org/bvsacd/cd38/Colombia/R769-02.pdf

Naciones Unidas. (1992). Convenio sobre diversidad biológica. Obtenido de https://www.cbd.int/doc/legal/cbd-es.pdf

Negrete, R. (2013). Derechos Minería y Conflictos. Aspectos Normativos. En L. Garay, Mineria en Colombia, Fundamentos para superar el modelo extractivita. Contraloria General de la República.

Perez, G. (2013). La delimitación del páramo y la incierta gestióde los servicios ecosistémicos de la alta montaña en escenarios de cambio ambiental. En J. Cortés, \& C. Sarmiento, Visión socioecosistémica de los páramos y la alta montaña colombiana: memorias del proceso de definición de criterios para la delimitación de páramos (págs. 127-139). Bogotá: Instituto de Investigación de Recursos Biológicos Alexander von Humboldt.

Reyes Garcés, H. M. (2014). Los daños ecológicos puros y la tragedia de los comunes: ¿existe una respuesta desde la justicia correctiva? Revista Academia \& Derecho, 5(9), 51-82. 
Presidencia Republica de Colombia. (1 de julio de 2010). Decreto 2372 de 2010. Bogotà, Colombia. Obtenido de http://faolex.fao.org/docs/pdf/col96046.pdf

Presidente Repùblica de Colombia. (18 de diciembre de 1974). Decreto 2811 de 1974. Bogotà, Colombia. Obtenido http://www.alcaldiabogota.gov.co/sisjur/normas/Norma1.jsp?i=1551

Temas Educativos. (5-16 de junio de 1972). Declaraciòn de la conferencia de las Naciones Unidas sobre el medio ambiente humano. Obtenido de Temas Educativos: http://www.jmarcano.com/educa/docs/estocolmo.html

Vargas, O. (2013). Disturbios en los páramos andinos. En J. Cortés, \& Sarmiento, Visión socioecosistémica de los páramos y la alta montaña colombiana: memorias del proceso de definición de criterios para la delimitación de páramos (págs. 39-57). Bogotà: Min Ambiente e Instituto de Investigación de Recursos Biológicos Alexander von Humboldt. Bogotá, D.C.

Vásquez, A., \& Buitrago, A. (2011). El gran libro de los páramos. Bogotá, D. C.: . Instituto de Investigación de Recursos Biológicos Alexander von Humboldt. Proyecto Páramo Andino. Obtenido de Https://rds.org.co/documentos/el_gran_libro_de_los_paramos 


\section{Ana Garcia}

Licenciada en Biología y Química. Esp.en Orientación Vocacional y Ocupacional. Docente Universidad Libre, Seccional Cúcuta. Correo electrónico institucional: ana.garcia@unilibrecucuta.edu.co.

\section{Yamal Elias Leal Espear}

Abogado Esp.Derecho Probatorio, Administrativo, Penal, Magister en Gestión de la calidad de la Educación superior. Docente investigador Universidad Libre, Seccional Cúcuta. Correo electrónico institucional: yamal.leal@unilibrecucuta.edu.co. 